Editorial

Paediatrics Today 2016;12(1):1-2

DOI $10.5457 / \mathrm{p} 2005-114.130$

\title{
UPDATES ON SOME CURRENT ISSUES IN PAEDIATRIC IMAGING
}

\author{
Veronica DONOGHUE* \\ Radiology Department, The National \\ Maternity Hospital, Dublin, Ireland \\ ${ }^{*}$ Corresponding author: \\ vdonoghue@gmail.com \\ Tel.: + 3531637352
}

Received/Accepted: February 2, 2016

Key words: Radiation exposure -

Ultrasound contrast agents • Fetal MR Imaging.

In recent years there has been an increase in demand for medical imaging procedures, many of which involve exposure to ionizing radiation. As a result, there are increasing concerns regarding the late adverse effects of radiation, particularly when the procedures are performed in the paediatric age group, which are estimated to be $2-5$ times higher than in the adult population. Attempts are being made by the ESR Eurosafe programme in conjunction with the European Society of Paediatric Radiology, and also the Image Gently campaign in the USA to highlight these concerns, to establish dose reference levels, and to encourage their use and the use of imaging referral guidelines. Recent studies suggest, however, that there is a lack of knowledge among clinicians (including radiologists) and radiographers concerning the need to establish justification for all imaging studies, the radiation doses involved and risks associated with many commonly performed imaging studies (1).

It is very timely therefore that the papers published in this issue pay considerable attention to such important issues as the appropriate use of immobilization and protection equipment (2), necessary to achieve good quality studies, without the need for repeat examina- tions. It is universally accepted that the use of an antiscatter grid requires an increase in radiation exposure in paediatric radiography, and it is very important that we have confirmation in this issue that this finding is also true when digital radiography is used (3).

Since the introduction to the market of more stable second generation ultrasound contrast agents, together with the introduction of harmonic ultrasound imaging, the technique of contrast enhanced voiding urosonography has proven to be valid and sensitive, in experienced hands, and is the procedure of choice in many central European countries to detect vesicoureteric reflux. The review papers in this issue give a detailed account of the technique, and discuss the safety issues together with the advantages of its use $(4,5)$. While the relationship between urinary tract infection, vesicoureteric reflux and renal scarring remains controversial, and the indications for studies to detect reflux are decreasing, it is important where possible to use examinations which are not associated with radiation exposure. To date, the indications for intravenous contrast enhanced sonography are very limited.

The role of ultrasonography in the diagnosis and monitoring of chronic liver diseases is well known. Recent developments in ultrasound elastography are very well addressed here (6) and though further research is needed, they point to elastography as a potentially useful tool in assessing the extent and progression of chronic liver diseases in children. This will be especially welcome in patients who suffer from cystic fibrosis, where there are many developments in the treatment of their pulmonary abnormalities, which leads in turn to a much increased life ex- 
pectancy. The growth in the incidences of childhood obesity and childhood diabetes is giving rise to an increased incidence of non-alcoholic fatty liver disease. Close monitoring of liver status is required in this patient population in order to prevent long-term significant morbidity.

The case report on the use of ultrasonography in a patient with pneumonia highlights the value of this modality for this condition (7). It may obviate the need for a CT examination. Ultrasound is helpful in assessing whether a pleural effusion contains clear fluid or not, in assessing if the effusion contains multiple locules, and in predicting the success of chest drain insertion or the need for a video-assisted thorascopic surgery procedure. It can also detect the presence of areas of necrotizing pneumonia.

Sonography with Doppler is invaluable in assessing acute scrotal abnormalities, common in young boys, and as discussed here (8) it easily identifies those patients with testicular torsion who require urgent surgical exploration.

Foetal ultrasonography is the standard imaging modality used to examine the foetus. Most congenital chest abnormalities are now diagnosed and monitored antenatally using sonography. This is also true of most renal tract abnormalities. As discussed in the paper addressing World Kidney Day 2016 (9), in much of the world this permits early intervention and as a result prevents long-term morbidity.

MR Imaging is useful in some conditions, such as right-sided diaphragmatic hernias, when ultrasound assessment is proving difficult. Foetal MR Imaging, as discussed here (10), when available, has become increasingly important in the prenatal evaluation of many of the brain abnormalities detected on the ultrasound examination. It is used to confirm the abnormalities detected and to exclude additional congenital abnormalities, such as cortical dysplasia and agenesis of the corpus callosum, which are difficult to detect on sonography. MR is sensitive at detecting blood products and frequently helps to provide the cause of ventriculomegaly, one of the commonest abnormalities detected in the foetal brain on sonography. It therefore provides very useful additional information, which is very important to obstetricians and geneticists involved in prenatal counselling.

In conclusion, this issue covers a variety of conditions in the paediatric population which require imaging. Attention is given to modalities, such as ultrasonography and MR Imaging, which do not require exposure to ionizing radiation and where there have been many advances in recent years. Important issues relating to radiation protection are also highlighted.

Conflict of interest: The author declares that she has no conflict of interest.

\section{References}

1. Portelli JL, McNulty JP, Bezzina P, Rainford L. Paediatric imaging radiation dose awareness and use of referral guidelines amongst radiology practitioners and radiographers. Insights Imaging. 2016;7(1):145-53.

2. Klavs D, Pašagić Dž, Kotar N. Radiation protection in pediatric radiography -Introducing some immobilization and protection equipment. Paediatrics Today. 2016;12(1):81-86.

3. Šabič I, Ključevšek D, Thaler M, Žontar D. The effect of anti-scatter grid on radiation dose in chest radiography in children. Paediatrics Today. 2016;12(1):75-80.

4. Ključevšek D. Contrast-enhanced ultrasonography in children. Paediatrics Today. 2016;12(1):49-55.

5. Cvitković Roić A, Roić G, Palčić I, Jaklin Kekez A. Contrast-enhanced voiding urosonography (cevus) as a diagnostic tool in evaluation of vesicoureteral reflux. Paediatrics Today. 2016;12(1):56-65.

6. Sleman IH, Liszewski MC. Ultrasound elastography in the noninvasive diagnosis of liver disease in children: A review. Paediatrics Today. 2016;12(1):41-8.

7. Meštrović Popovič K, Trunkl P, Šibanc B. The value of lung ultrasonography in a child with pneumonia. Paediatrics Today. 2016;12(1):113-4.

8. Roić G. Sonography of the acute scrotum in children. Paediatrics Today. 2016;12(1):66-74.

9. Ingelfinger JR, Kalantar-Zadeh K, Schaefer F. World kidney day 2016 averting the legacy of kidney disease--focus on childhood. Paediatrics Today. 2016;12(1):115-23.

10. Vipotnik Vesnaver T. A peek into the uterus - MRI of the fetal CNS. Paediatrics Today. 2016;12(1):3-15. 